\title{
BIONOMIC NOTES ON THE SATYRID BUTTERFLY Oeneis macounii AT RIDING MOUNTAIN, MANITOBA
}

\author{
by John H. Masters, Box 7511, Saint Paul and \\ John T. Sorensen, 5309 - 37th Ave. S., Minneapolis
}

The Macoun's Arctic Butterfly, Oeneis macounii (Edwards), like some others in its genus, has a two year life cycle and flies only in alternate years. From Riding Mountain westward it flies in odd-numbered years, while to the east it flies in even-numbered years. We observed (Masters et al, 1967) that the habitat of this butterfly in Minnesota and eastern Manitoba is open jack pine forest. Both sexes, which were captured in almost equal numbers, could be distinguished from a distance while on the wing because of differences in flight behaviour. Females fly slowly and aimlessly through the pine forest and are readily netted. Males, more active and harder to capture, select favourite perches that serve as observation points over small clearings, and from such vantage points they wait for a female and drive away other males that come into view. When a territorial male is captured, he will often be replaced by a new male in an hour or two, the latter frequently using the same perch. Both sexes were observed to land in sunlit spots with wings open; only infrequently would one close its wings.

We now have some further observations of this species at Riding Mountain where it was again found in open jack pine forests, though favouring higher points along ridges. Males preferred small sunlit openings in the forest or along trails; females, on the other hand, ranged more widely and sometimes were captured at a distance

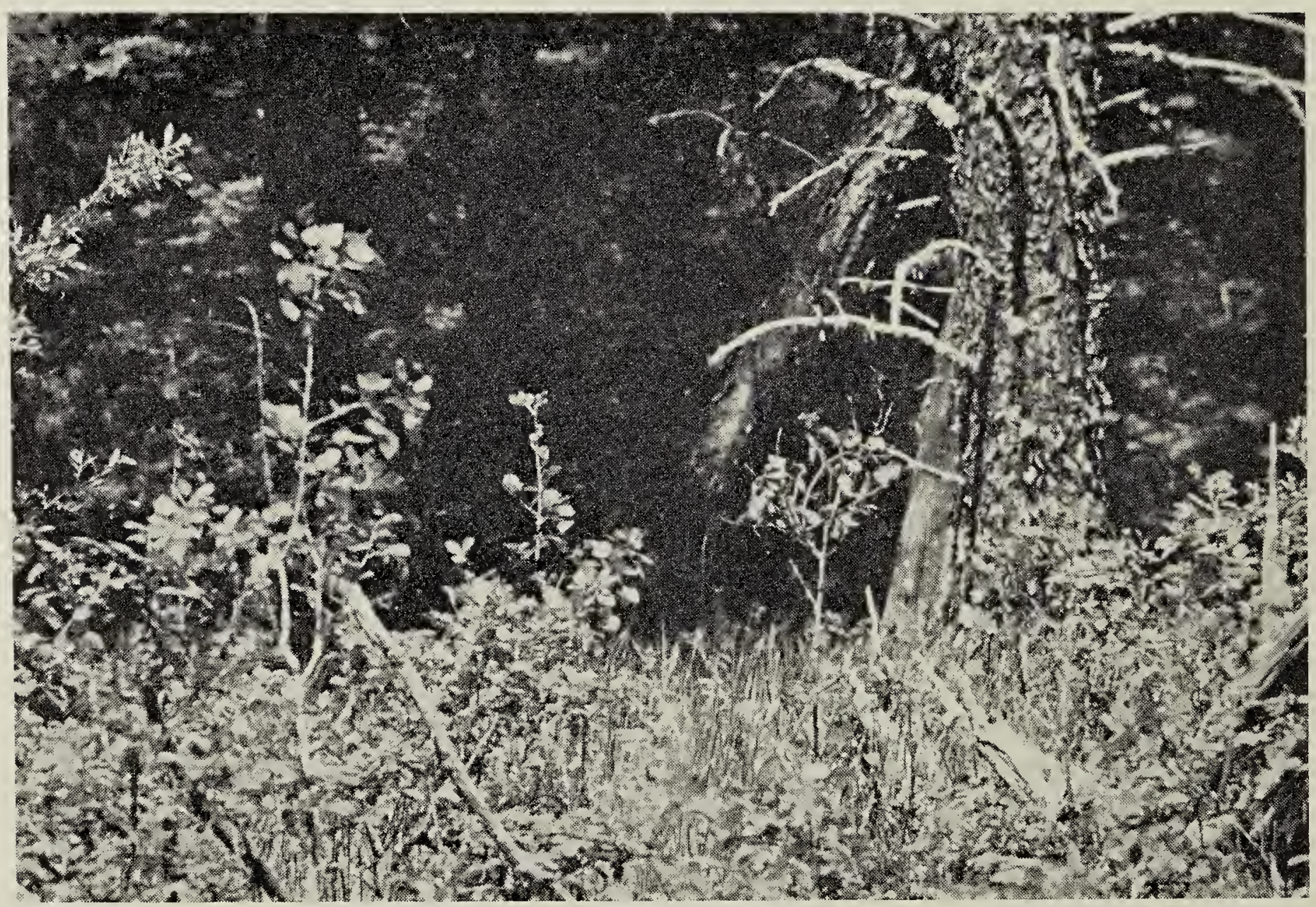

Forest clearing, Riding Mountain, Manitoba -typical habitat for Oeneis macounii. 
from the pines-one was found in the middle of a large field.

Our observations were made over a three day period with three correspondingly different weather conditions. On June 23, a cold, cloudy day with the temperature never exceeding $55^{\circ} \mathrm{F}$., no macounii were seen to fly and the only ones located were hanging on the undersides of leaves near the ground-one copulating pair was found in this situation. On June 24, with a clear sky and the temperature reaching $68^{\circ} \mathrm{F}$., butterflies were active and always landed in sunlit areas with their wings open. On June 25, quite hot for Riding Mountain at $80^{\circ} \mathrm{F}$., the butterflies were still active but after alighting they would quickly fold their wings over their backs and would sometimes lean slightly away from the sun. These behavioural differences are related to thermoregulation, a subject taken up in detail by Clench (1966). Clench cites the importance of thermoregulation to butterfly behaviour and concludes that the opening and closing of wings is one of several devices that permit control of the amount of solar heat received, the wings being the butterflies' primary area for heat exchange. Clench cites six distinct heat zones for butterfly activity:

1. Lethal heat (limits unknown, probably well over $100^{\circ} \mathrm{F}$ ).

2. Cooling dominant. Normal activity suspended; cooling activity only $\left(90^{\circ} \mathrm{F}\right.$ and over; upper limit not known).

3. Normal activity. Feeding courtship, mating, active flight, etc. This has three subdivisions:

A. Normal activity combined with auxiliary cooling (circa 85-90 ${ }^{\circ} \mathrm{F}$ ).

B. Vernier control (circa 75$\left.85^{\circ} \mathrm{F}\right)$.

C. Normal activity combined with auxiliary heating (circa $68-75^{\circ}$ ).

4. Warming dominant. Basking the major activity $\left(\operatorname{circa} 58-68^{\circ} \mathrm{F}\right)$.

5. Inactive (below $58^{\circ} \mathrm{F}$, lower limit unknown).

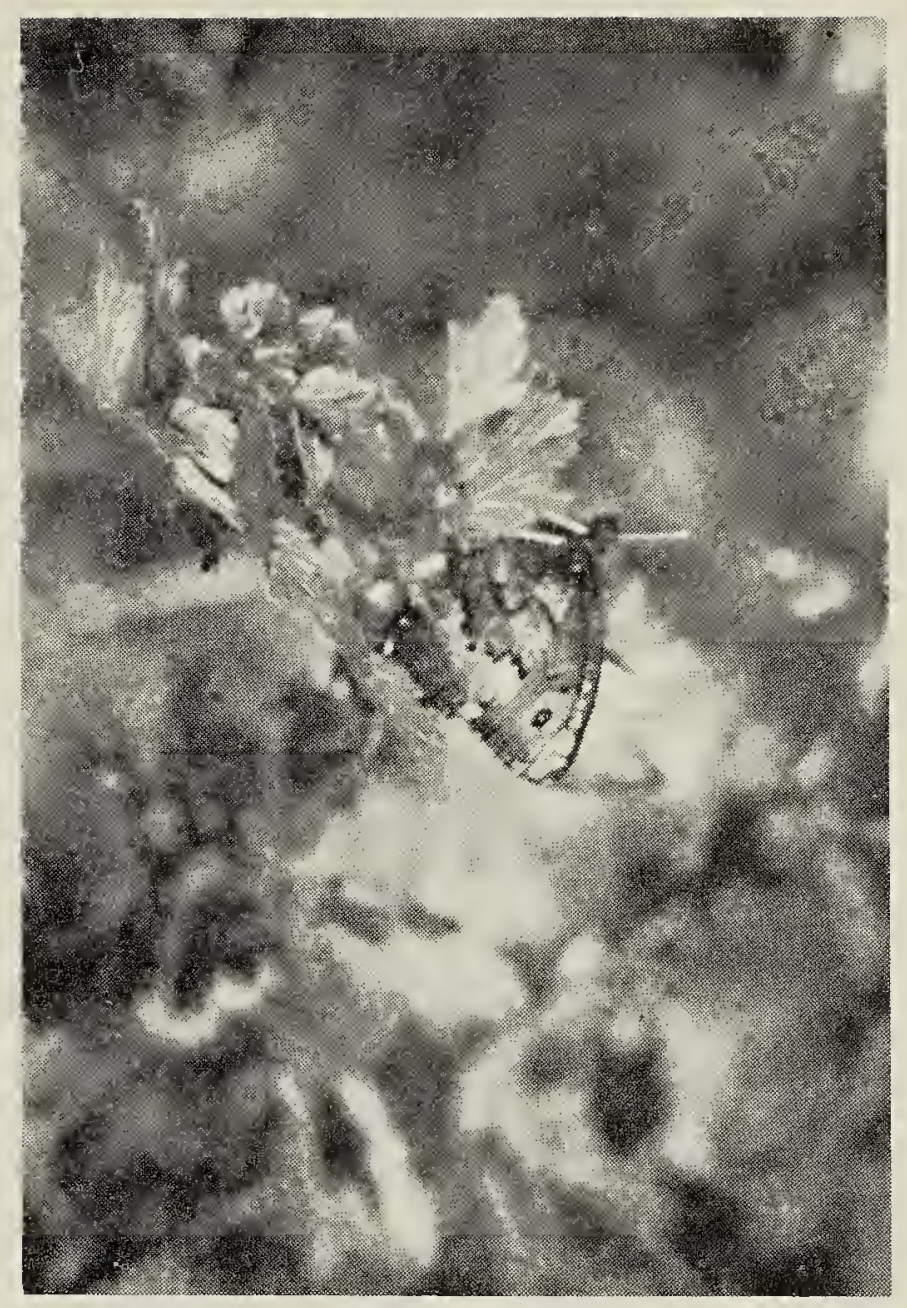

Oeneis macounii.

6. Lethal cold (boundary value unknown).

Our observations with $O$. macounii correlate rather well with Clench's data if the temperature values are adjusted to slightly lower temperatures. For other Oeneis, such as $O$. alberta Elwes (Brown, 1952) the temperature values seern to be significantly lower.

Huber (1965) observed two macounii alighting with closed wings and angling towards the sun and interpreted this as a method of concealment rather than thermoregulation. We observed macounii alighting on rocks only infrequently, though they did then close their wings and once one leaned slightly away from the sun. Listing in the sun was the subject of an early paper by Longstaff (1908) who observed other satyrid butterflies, including the closely related European Satyrus semele (Linnaeus). Longstaff observed that satyrids would sometimes list (lean to one side) while sitting 
with folded wings; he then demonstrated that this cannot be a function of concealment because the angle of the list is too small to hide the shadow, which in most cases was actually lengthened. Dr. Longstaff, who was concerned primarily with mimicry and protective behaviour, concluded that "So far as regards the shadow cast, no list from the sun can be protective to the insect unless it be extreme. Again, a list from the sun by resulting in the maximum illumination of the wing surface, can hardly aid concealment, at the same time, it cannot be denied that a butterfly by placing itself out of the upright, may thereby be protected in so far as it may then be more difficult to detach i.t from its surroundings." Dr. Longstaff rejected the concealment theory, but did not have an alternative for it, such as we now have, based on thermoregulation. It is not plausible that concealment would be a temperature regulated activity (i.e. occurring only above $\left.80^{\circ} \mathrm{F}\right)$, and, in spite of the cryptic undersides of macounii, concealment during the active flying hours appears not to occur.

Territorialism in $O$. macounii appears to function for the purpose of acquiring a mate (Masters, et al 1967). A territory usually consists of a small glade in which the male has a strategic perch from where he can observe the entire area. The butterflies have definite instincts regarding special orientation in a glade as pertains to selecting an ideal perch. If you remain stationary in a glade, the butterflies will become quite unaware of you and can be observed at close range. Several times we (JHM) observed that a particular butterfly would alight again and again on a particular perch. It seemed a simple matter to move a camera and tripod into the glade to focus on this perch and wait; however, the presence of observer and camera seemed to alter the topography of the clearing from the butterfly's point of view and another perch would be selected-most frequently closer to the new obstruction in the clearing and too close for the camera to focus on it. One butterfly, that had been observed for some time, was captured and allowed to be replaced by another male; the habits of the replacement and his selection of perches were almost identical with those of his predecessor. Selection of a favoured perch was apparently also dependent upon the angle of the sun; therefore, in any particular glade the favoured perch would vary during the day. This seemed to be more dependent upon changing shadows in the glade that provided better vision from one spot rather than upon thermoregulation. The nature of the favourite perch did not seem to be as important as its location. Most often it was among green leaves on a tree branch or at the top of a low bush, but frequently it was on a bare twig. Males occasionally alighted on fallen logs, rocks or bare earth, but only momentarily and they quickly returned to a higher perch.

Feeding seemingly played a minor role in macounii's daily behaviour. Regularly used glades usually contained a few flowers which were visited for brief periods throughout the day, although each time the butterfly would then quickly return to its favourite perch on a tree or shub.

\section{Acknowledgements}

We gratefully acknowledge the assistance of John Polusny and C. S. Quelch of Winnipeg for aiding us in locating the macounii habitat; and Dr. Richard M. Fox of the Carnegie Museum and Dr. Robert W. Nero of the Manitoba Museum of Man and Nature, both of whom read our manuscript and made helpful suggestions.

\section{LITERATURE CITED}

Brown, F. M. 1952. Oeneis oslari Skinner, rediscovered. Ent. News, $63: 119-122$.

Clench, H. K. 1966. Behavioral thermoregulation in butterflies. Ecology, $47: 1021-1034$.

Huber, R. L. 1965. Another U.S. record for Oeneis macounii. J. Lep. Soc., 19:125.

Longstaff, G. B. 1909. Bionomic notes on butterflies. Trans. Ent. Soc. London, 607-673.

Masters, J. H., J. T. Sorensen and P. J. Conway. 1967. Observations on Oeneis macounii in Manitoba and Minnesota. In Press. J. Lep. Soc., $21(4)$. 